\title{
Prevalence of Toxocara canis eggs in dog faeces from public places of Florence, Italy
}

\author{
R. PAPINI ${ }^{1}$, E. CAMPISI ${ }^{2}$, E. FAGGI ${ }^{2}$, G. PINI ${ }^{2}$, F. MANCIANTI ${ }^{1}$ \\ ${ }^{1}$ Department of Animal Pathology, Prophylaxis and Food Hygiene, University of Pisa, Viale delle Piagge 2, \\ 56124 Pisa, Italy, E-mail: rpapini@vet.unipi.it; ${ }^{2}$ Public Health Department, University of Florence, \\ Viale Morgagni 48, 50134 Florence, Italy
}

\begin{abstract}
Summary
To determine whether canine faecal contamination may represent a source of environmental contamination with Toxocara canis eggs within the urban area of Florence, a total number of 754 dog faeces were collected in 7 public places and examined by routine floatation technique during one-year period. The total prevalence of intestinal nematode eggs was $8.6 \%$. Trichuris vulpis (4.6\%) eggs were the most prevalent followed by $T$. canis $(3.6 \%$ ) and Ancylostomidae $(1.7 \%)$ eggs. Mixed infections included T. canis/T. vulpis $(0.7 \%)$, Ancylostomidae/T. canis $(0.4 \%)$, and Ancylostomidae/T. vulpis $(0.3 \%)$. Total prevalence of intestinal nematode eggs was significantly higher in spring than in winter $(\mathrm{OR}=2.06)$. Our results indicate a low prevalence of $T$. canis eggs suggesting that dog faeces left on soil are unlikely to cause high environmental contamination with $T$. canis eggs in the town of Florence.
\end{abstract}

Keywords: dog faeces; Toxocara canis; environmental contamination

\section{Introduction}

Toxocara canis Werner 1782 (Family Ascarididae, Superfamily Ascaridoidea) is a common roundworm of dogs and other canids with worldwide distribution. Adult helminths live in the small intestine of definitive hosts where mating and egg laying occur. T. canis females have a life span of about four months and can release up to 100,000 eggs per day. Puppies of up to three months of age pose the greatest risk of harbouring the infection and can shed up to 15,000 eggs per gram of faeces daily. Thus millions of $T$. canis eggs can be passed in the environment through faecal route (Richards \& Lewis, 2001). Faeces decompose with time releasing eggs which cumulate into the surrounding soil. $T$. canis eggs occurred in $7.8-62.5 \%$ of soil samples collected in various countries (Tinoco-Gracia et al., 2007; Tavassoli et al., 2008). The eggs are very resistant to both chemical agents and climatic factors but do not embryonate at $<12{ }^{\circ} \mathrm{C}$ though survive at $-25{ }^{\circ} \mathrm{C}$, and are susceptible to both heat $\left(40{ }^{\circ} \mathrm{C}\right)$ and desiccation. Under appropriate conditions of temperature $\left(15-30{ }^{\circ} \mathrm{C}\right)$, humidity $(85 \%)$, shade, and oxygen, eggs develop containing an infective L2 larva once fully embryonated. Because of variation and interaction between these factors, the eggs probably need at least $10-14$ days before becoming infective in nature. In studies of soil contamination, up to $46.9 \%$ of recovered eggs remained viable, able to embryonate and thus presumably to infect (Dubná et al., 2007). Survival in an appropriate external environment for at least six months has been reported (Dunsmore et al., 1984).

Infection of definitive hosts can occur by ingestion of infective eggs from contaminated soil, food or drink, by ingestion of L2 infective larvae from tissues of paratenic hosts, or by transplacental transmission. Paratenic and accidental hosts, including humans and a number of various mammals, can be infected by ingestion of infective $T$. canis eggs. Second stage larvae hatch in the small intestine and migrate through organs and tissues, most commonly the lungs, liver, eyes, and brain. The migration of $T$. canis larvae in humans results in three main syndromes: visceral larva migrans (VLM), which encompasses diseases associated with major organs; covert toxocariasis, which is a milder form of VLM; and ocular larva migrans (OLM), in which pathological effects on the host are restricted to the eye and the optic nerve (Despommier, 2003).

Soil contamination of urban and suburban areas with high dog densities appears to be a particularly insidious, long term reservoir of $T$. canis infection to humans (Gawor et al., 2008). In order to estimate the potential zoonotic risk and implement prevention and control strategies, direct examination searching the eggs in soil samples is necessary. However, this is labour intensive and time consuming as large amounts of soil should be examined to accurately determine the frequency of $T$. canis eggs (Duwel, 
1984). Examination of faecal samples is more feasible than examination of soil samples and evaluation of the prevalence of $T$. canis eggs in canine faeces contaminating urban areas may be useful to replace or supplement studies assessing the risk of environmental contamination (Maśnik, 2000; Noor Azian et al., 2008). Moreover, the environmental contamination with $T$. canis eggs in a given area can be related to the occurrence of human toxocariasis (Gawor et al., 2008). Thus the aim of the present study was to determine the prevalence of $T$. canis eggs in dog faeces collected in public places of the town of Florence.

\section{Materials and methods}

\section{Study area}

Florence $\left(43^{\circ} 47^{\prime} 14^{\prime \prime} 64 \mathrm{~N}, 11^{\circ} 14^{\prime} 59^{\prime \prime} 64 \mathrm{E}\right)$ is the capital city of Tuscany (Central Italy). It rises 50 metres above the sea level, has a population of about 368,362 inhabitants and a surface of 102.41 square kilometres, thus showing a population density of 3,596.9 inhabitants per square kilometre. Florence is also the heart of a metropolitan area of over $1,500,000$ inhabitants. An estimated population of 26,000 owned dogs is currently living in the municipality of Florence, giving a density of 254 dogs per square kilometre. Stray dogs practically do not occur as they are quickly caught and transported to a municipal shelter. The effort to manage canine faecal contamination is focused on encouraging all dog owners to collect faeces from their pets when deposited in public places. However, although many owners comply with municipal laws collecting faeces into a plastic bag while they are walking with their dogs, some faecal deposits are not diligently picked up.

\section{Collection of samples}

Between January and December 2009, a total of $754 \mathrm{dog}$ faeces were collected from 7 distinct public places (A to $\mathrm{G})$ within the urban area of Florence. Public places were randomly selected and sampled 4 times during one year period (once each season). Sampled areas were densely built-up with inhabitants of mixed background and had completely free access at any time without any kind of fence. Each area was walked through in a parallel row between 8 and 10 AM. Well-formed, fresh dog faecal de- posits were sampled. All samples were of canine origin as judged by their size, aspect, and deposition place (on the surface and not buried in the ground). A faecal deposit was estimated to be fresh, i.e. released within 24 hours, by direct observation depending on the moisture content and overall weathered appearance. To reduce the chance of collecting multiple samples from the same dog, only a single sample was collected when multiple deposits were found well-close at a site. From each area, 8 to 49 faecal samples were collected at the time of sampling and a total number of 62 to $123 \mathrm{dog}$ faeces were examined (Table 2). Samples were put in clean plastic containers, marked according to area and date of collection, brought to the laboratory as soon as possible, and kept at $4{ }^{\circ} \mathrm{C}$ until processing, which was carried out within $24 \mathrm{~h}$.

\section{Faecal flotation technique}

Coprological samples were examined by routine flotation technique. Briefly, $3-5$ grams of faecal sample were mixed thoroughly with a saturated $\mathrm{NaCl}$ solution (sp. gr. 1.2 ) yielding a homogenous suspension which was filtered through a 60 mesh sieve. Then, flotation was performed with test tubes filled to the top with the faecal suspension. A cover glass was placed on top for 15 minutes, then removed, placed on a microscope slide, and examined under 100x magnification. The presence of intestinal parasites other than $T$. canis was also taken into consideration during the coprological study. T. canis and other helminth eggs were identified according to morphological characteristics and micrometric measurements. Each sample was considered as positive when at least one nematode egg was found.

\section{Statistical analysis}

Prevalence of intestinal nematode eggs was determined as number of positive samples/number of examined samples X 100 along with corresponding $95 \%$ confidence intervals ( $95 \%$ CI). Total positivity rates were compared according to area and season. For this purpose, the chi-square test was carried out and odds ratio (OR) values were also calculated. Values of $P<0.05$ and $P<0.01$ were considered significant or highly significant, respectively.

Table 1. Distribution of nematode eggs in dog faeces from public places (A to G) of Florence, Italy

\begin{tabular}{lcccccccc}
\hline Nematode eggs & \multicolumn{9}{c}{ Sampled areas } & & $\begin{array}{c}\text { Total prevalence } \\
\text { in areas } \\
\text { (n= 754) }\end{array}$ \\
\hline & $\mathrm{A}$ & $\mathrm{B}$ & $\mathrm{C}$ & $\mathrm{D}$ & $\mathrm{E}$ & $\mathrm{F}$ & $\mathrm{G}$ \\
$(\mathrm{n}=114)^{\mathrm{a}}$ & $(\mathrm{n}=123)$ & $(\mathrm{n}=114)$ & $(\mathrm{n}=121)$ & $(\mathrm{n}=106)$ & $(\mathrm{n}=114)$ & $(\mathrm{n}=62)$ & \\
\hline Trichuris vulpis & $1^{\mathrm{b}}(0.9 \%)^{\mathrm{c}}$ & $10(8.1 \%)$ & $12(10.5 \%)$ & $2(1.6 \%)$ & $2(1.9 \%)$ & $2(1.7 \%)$ & $6(9.7 \%)$ & $35(4.6 \%)$ \\
& $(0-2.6 \%)^{\mathrm{d}}$ & $(3.3-13 \%)$ & $(4.9-16.2 \%)$ & $(0-3.9 \%)$ & $(0-4.5 \%)$ & $(0-4.2 \%)$ & $(2.3-17 \%)$ & $(3.1-6.1 \%)$ \\
Toxocara canis & $4(3.5 \%)$ & $2(1.6 \%)$ & $5(4.4 \%)$ & $2(1.6 \%)$ & $1(0.9 \%)$ & $4(3.5 \%)$ & $9(14.5 \%)$ & $27(3.6 \%)$ \\
& $(0.1-6.9 \%)$ & $(0-3.9 \%)$ & $(0.6-8.1 \%)$ & $(0-3.9 \%)$ & $(0-2.8 \%)$ & $(0.1-6.9 \%)$ & $(5.7-23.3 \%)$ & $(2.2-4.9 \%)$ \\
Ancylostomidae & $2(1.7 \%)$ & 0 & $2(1.7 \%)$ & $2(1.6 \%)$ & 0 & $2(1.7 \%)$ & $5(8.1 \%)$ & $13(1.7 \%)$ \\
& $(0-4.2 \%)$ & & $(0-4.2 \%)$ & $(0-3.9 \%)$ & & $(0-4.2 \%)$ & $(1.3-14.8 \%)$ & $(0.8-2.6 \%)$ \\
\hline
\end{tabular}

${ }^{a}$ Number of samples examined; ${ }^{b}$ Number of positive samples; ${ }^{c}$ Prevalence; ${ }^{d} 95 \%$ confidence interval 
Table 2. Distribution of mixed infections in dog faeces from public places (A to G) of Florence, Italy

\begin{tabular}{|c|c|c|c|c|c|c|c|c|}
\hline \multirow[t]{2}{*}{ Nematode eggs } & \multicolumn{7}{|c|}{ Sampled areas } & \multirow{2}{*}{$\begin{array}{l}\text { Total prevalences } \\
\text { in areas }(n=754)\end{array}$} \\
\hline & $\begin{array}{c}\mathrm{A} \\
(\mathrm{n}=114)^{\mathrm{a}}\end{array}$ & $\begin{array}{c}\mathrm{B} \\
(\mathrm{n}=123)\end{array}$ & $\begin{array}{c}\mathrm{C} \\
(\mathrm{n}=114)\end{array}$ & $\begin{array}{c}\mathrm{D} \\
(\mathrm{n}=121)\end{array}$ & $\begin{array}{c}E \\
(n=106)\end{array}$ & $\begin{array}{c}\mathrm{F} \\
(\mathrm{n}=114)\end{array}$ & $\begin{array}{c}\mathrm{G} \\
(\mathrm{n}=62)\end{array}$ & \\
\hline T. canis/T. vulpis & $0^{\mathrm{b}}$ & 0 & $\begin{array}{c}1(0.9 \%)^{\mathrm{c}} \\
(0-2.6 \%)^{\mathrm{d}}\end{array}$ & 0 & 0 & $\begin{array}{c}1(0.9 \%) \\
(0-2.6 \%)\end{array}$ & $\begin{array}{c}3(4.8 \%) \\
(0-10.2 \%)\end{array}$ & $\begin{array}{c}5(0.7 \%) \\
(0.1-1.2 \%)\end{array}$ \\
\hline Ancylostomidae/T. canis & 0 & 0 & 0 & 0 & 0 & 0 & $\begin{array}{c}3(4.8 \%) \\
(0-10.2 \%)\end{array}$ & $\begin{array}{c}3(0.4 \%) \\
(0-0.8 \%)\end{array}$ \\
\hline Ancylostomidae/T. vulpis & 0 & 0 & $\begin{array}{c}2(1.7 \%) \\
(0-4.2 \%)\end{array}$ & 0 & 0 & 0 & 0 & $\begin{array}{l}2(0.3 \%) \\
(0-0.6 \%\end{array}$ \\
\hline
\end{tabular}

${ }^{\mathrm{a}}$ Number of samples examined; ${ }^{b}$ Number of positive samples; ${ }^{\mathrm{c}}$ Prevalence; ${ }^{\mathrm{d}} 95 \%$ confidence interval

\section{Results}

At the time of sampling, dog faeces were always visible in all the areas examined. However, the total amount of dog faeces in each area was not evaluated as it didn't fall within the aim of the present study. Intestinal nematode eggs could be found in all the public places examined and their distribution is shown in Table 1. Overall, 8.6\% (95\% CI: $6.6-10.6 \%$ ) of samples were found to be positive for nematode eggs. Trichuris vulpis $(4.6 \%)$ was the most prevalent followed by T. canis $(3.6 \%)$, and Ancylostomidae $(1.7 \%)$. The distribution of mixed infections is shown in Table 2. As expected, all eggs were found to be unembryonated.

The prevalence values of intestinal nematode eggs according to area and season are shown in Table 3. During the whole study period, no positive faecal samples were detected in 7 cases, while positivity rates in single samplings ranged from $2.2 \%$ to $83.3 \%$. The total prevalence of intestinal nematode eggs ranged from $2.8 \%$ to $22.6 \%$ according to area and from $6 \%$ to $11.6 \%$ according to season. A statistically significant difference between spring and winter was detected $\left(\mathrm{p}=0.0479 ; \chi^{2}=3.915 ; \mathrm{OR}=2.06\right.$ [95\% CI $=0.99$ - 4.29]).

\section{Discussion}

The presence of parasitic agents associated with canine faecal contamination is not an unexpected finding (Legrottaglie et al., 2003; Rinaldi et al., 2006; PaquetDurand et al., 2007; Martin \& Demonte, 2008). T. canis prevalence in soil samples varies not only from country to country but also in different regions within a country. Reasons for variation include, but are not restricted to, environmental conditions, choice of sampling sites, the utilization of the area by dogs, and the prevalence of infection in dogs in the area. With respect to similar studies, the present prevalence of $T$. canis eggs $(3.6 \%)$ is much lower than the range of prevalence rates ( $7 \%$ to $25.7 \%$ ) reported in various countries around the world including Italy (Legrottaglie et al., 2003; Paquet-Durand et al., 2007; Martin \& Demonte, 2008). However, it is higher than 0.7 $\%$ found in another investigation carried out in this country (Rinaldi et al., 2006).

Since the successful development of intestinal nematode eggs depends on favourable climate conditions, this probably resulted in the statistically significant increase of transmission observed in our survey during spring with respect to winter. In particular, the likelihood of $T$. canis

Table 3. Dog faeces positive to intestinal nematode in public places (A to G) of Florence according to season

\begin{tabular}{|c|c|c|c|c|c|}
\hline \multirow[t]{2}{*}{ Sampled areas } & \multicolumn{4}{|c|}{ Seasons } & \multirow{2}{*}{$\begin{array}{c}\text { Total prevalences } \\
\text { in areas }\end{array}$} \\
\hline & Winter & Spring & Summer & Fall & \\
\hline $\mathbf{A}$ & $0^{\mathrm{a}} / 34^{\mathrm{b}}$ & $\begin{array}{l}2 / 24(8.3 \%)^{\mathrm{c}} \\
(0-19.4 \%)^{\mathrm{d}}\end{array}$ & $0 / 8$ & $\begin{array}{l}5 / 48(10.4 \%) \\
(1.8-19.1 \%)\end{array}$ & $\begin{array}{l}7 / 114(6.1 \%) \\
(1.7-10.5 \%)\end{array}$ \\
\hline B & $0 / 27$ & $\begin{array}{l}5 / 24(20.8 \%) \\
(4.6-37.1 \%)\end{array}$ & $\begin{array}{l}4 / 24(16.7 \%) \\
(1.8-31.6 \%)\end{array}$ & $\begin{array}{l}3 / 48(6.2 \%) \\
(0-13.1 \%)\end{array}$ & $\begin{array}{c}12 / 123(9.8 \%) \\
(4.5-15 \%)\end{array}$ \\
\hline C & $\begin{array}{c}3 / 24(12.5 \%) \\
(0-25.7 \%)\end{array}$ & $\begin{array}{c}3 / 24(12.5 \%) \\
(0-25.7 \%)\end{array}$ & $\begin{array}{l}2 / 18(11 . \%) \\
(0-25.6 \%)\end{array}$ & $\begin{array}{l}8 / 48(16.7 \%) \\
(6.1-27.2 \%)\end{array}$ & $\begin{array}{c}16 / 114(14 \%) \\
(7.7-20.45)\end{array}$ \\
\hline D & $\begin{array}{c}2 / 49(4.1 \%) \\
(0-9.6 \%)\end{array}$ & $0 / 24$ & $\begin{array}{l}1 / 24(4.2 \%) \\
(0-12.2 \%)\end{array}$ & $\begin{array}{c}3 / 24(12.5 \%) \\
(0-25.7 \%)\end{array}$ & $\begin{array}{c}6 / 121(5 \%) \\
(1.1-8.8 \%)\end{array}$ \\
\hline $\mathbf{E}$ & $\begin{array}{c}1 / 46(2.2 \%) \\
(0-6.4 \%)\end{array}$ & $\begin{array}{l}1 / 19(5.3 \%) \\
(0-15.3 \%)\end{array}$ & $\begin{array}{l}1 / 17(5.9 \%) \\
(0-17.1 \%)\end{array}$ & $0 / 24$ & $\begin{array}{l}3 / 106(2.8 \%) \\
\quad(0-6 \%)\end{array}$ \\
\hline $\mathbf{F}$ & $\begin{array}{l}3 / 48(6.2 \%) \\
(0-13.1 \%)\end{array}$ & $\begin{array}{l}2 / 24(8.3 \%) \\
(0-19.4 \%)\end{array}$ & $0 / 18$ & $\begin{array}{l}2 / 24(8.3 \%) \\
(0-19.4 \%)\end{array}$ & $\begin{array}{l}7 / 114(6.1 \%) \\
(1.7-10.5 \%)\end{array}$ \\
\hline G & $\begin{array}{c}5 / 6(83.3 \%) \\
(53.5-100 \%)\end{array}$ & $\begin{array}{c}5 / 16(31.2 \%) \\
(8.5-54 \%)\end{array}$ & $0 / 16$ & $\begin{array}{l}4 / 24(16.7 \%) \\
(1.8-31.6 \%)\end{array}$ & $\begin{array}{c}14 / 62(22.6 \%) \\
(12.2-33 \%)\end{array}$ \\
\hline $\begin{array}{c}\text { Seasonal total } \\
\text { prevalences }\end{array}$ & $\begin{array}{c}14 / 234(6 \%) \\
(2.9-9 \%)\end{array}$ & $\begin{array}{c}18 / 155(11.6 \%) \\
(6.6-16.7 \%)\end{array}$ & $\begin{array}{l}8 / 125(6.4 \%) \\
(2.1-10.7 \%)\end{array}$ & $\begin{array}{c}25 / 240(10.4 \%) \\
(6.5-14.3 \%)\end{array}$ & $\begin{array}{c}65 / 754(8.6 \%) \\
(6.6-10.6 \%)\end{array}$ \\
\hline
\end{tabular}


eggs to become infectious may be hampered by heat, cold, low humidity, run-off by rainfall, and ovicidal activity of environmental fungi (Gortari et al., 2007). Even if T. canis eggs become infectious, they do not constitute a risk for humans unless are inadvertently ingested as in cases of soil pica. Dog faeces remained on soil of public places of Florence are unlikely to be a cause of high environmental contamination with $T$. canis eggs, as our results indicate a prevalence as low as $3.6 \%$. This is good because of the potential pathogenicity of VLM and OLM syndromes in humans. Nonetheless, other sources of T. canis exposure may lead to zoonotic infections. For instance, rural environments and surroundings of houses may be as contaminated by faeces of infected dogs as urban areas, or even more (Habluetzel et al., 2003; Gawor et al., 2008). Direct contacts with dogs and poor hygiene measures such as failure to wash properly hands, kissing dogs, or allow them licking on the face may be risk behaviours since embryonated eggs are sticky and can adhere to the coat of dogs (Aydenizöz-Ozkayan et al., 2008). Due to their defecation habits, cats may contaminate the environment with eggs of Toxocara cati (Matsuo and Nakashio, 2005) which can be in turn an agent of human toxocariasis, though differentiation of the two aetiological agents still remains challenging (Fisher, 2003).

We believe that the total low prevalence of $T$. canis in the faecal samples we surveyed may be attributed to various factors. The presence of adult dogs can decrease the probability of finding Toxocara eggs in their faeces, as adult dogs release less eggs than puppies. Stray dogs practically don't occur in Florence. High numbers of stray dogs are thought to contribute to large environmental contamination with T. canis eggs (Daryani et al., 2009). As stray dogs are quickly caught and transported to the Municipal shelter, the canine faecal samples examined mostly originated from privately owned dogs. As a result of the increased level of care towards pets, dogs receive better antiparasitic care. This aspect was reflected in an epidemiological investigation carried out in Italy which recorded the lowest $T$. canis infection rate in urban dogs kept as pets (Habluetzel et al., 2003). Another important factor may be the widespread use of better anthelmintics including heartworm control drugs. Some products licensed for heartworm control during recent years (i.e., selamectin, mylbemicine oxime) have shown a significant effect on intestinal parasitism by nematodes including T. canis (Guerrero et al., 2002).

Eggs of other helminths potentially transmissible to humans were also detected in this survey. Cases of intestinal infection with Trichuris vulpis adult worms (Dunn et al., 2002) and possible role in the VLM syndrome (Masuda et al., 1987) have been described in humans. Cutaneous larva migrans or "creeping eruption" is a disease of humans typically caused by dog or cat hookworm larvae of the genus Ancylostoma migrating into the skin. It is associated with linear or serpiginous, slightly prominent, pruritic, erythematous lesions. This condition occurs typically through contact with soil or sand contaminated with animal faeces, most frequently in warmer climates (Bowman et al., 2010). Autochthonous cases have been found in Italy (Morrone et al., 2008).

In conclusion, examination of dog faeces contaminating urban areas can provide useful data on the risk of environmental occurrence of $T$. canis and other helminth eggs which are potential causative agents of human diseases (Maśnik, 2000; Noor Azian et al., 2008). Our results suggest that the contamination with dog faeces represents a negligible source of exposure to $T$. canis eggs in the urban environment of Florence. In spite of this, it must be kept in mind that humans, mostly children, always take a risk of serious infection following accidental ingestion of infectious eggs. Therefore, it is still mandatory that dogs are regularly dewormed and excluded from playgrounds, canine faeces are properly disposed of, and personal hygiene is strictly observed.

\section{References}

AYDENIZÖZ-OZKAYHAN, M., YAĞCI, B. B., ERAT, S. (2008): The investigation of Toxocara canis eggs in coats of different dog breeds as a potential transmission route in human toxocariasis. Vet. Parasitol., 152(1 - 2): $94-100$. DOI: 10.1016/j.vetpar.2007.12.002

Bowman, D. D., Montgomery, S. P., Zajac, A. M., EBERHARD, M. L., KAZACOS, K. R. (2010): Hookworms of dogs and cats as agents of cutaneous larva migrans. Trends Parasitol., 26(4):162 - 167

Daryani, A., Sharif, M., Amouei, A., Gholami, S. (2009): Prevalence of Toxocara canis in stray dogs, northern Iran. Pak. J. Biol. Sci., 12(14): 1031 - 1035

DESPOMMIER, D. (2003): Toxocariasis: clinical aspects, epidemiology, medical ecology, and molecular aspects. Clin. Microbiol. Rev., 16(2): 265 - 272. DOI: 10.1128/ CMR.16.2.265-272.2003

DuBná, S., LANGRovÁ, I., JANKOVSKÁ, I., VADLEJCH, J., PEKÁR, S., NÁPRAVNÍK, J., FECHTNER, J. (2007): Contamination of soil with Toxocara eggs in urban (Prague) and rural areas in the Czech Republic. Vet. Parasitol., 144(1 2): 81 - 86. DOI: 10.1016/j.vetpar.2006.09.023

Dunn, J. J., Columbus, S. T., Aldeen, W. E., Davis, M., CARROLL, K. C. (2002): Trichuris vulpis recovered from a patient with chronic diarrhoea and five dogs. J. Clin. Microbiol., 40(7): 2703 - 2704. DOI: 10.1128/JCM.40.7.27032704.2002

Dunsmore, J. D., Thompson, R. C. A., BAtes, I. A. (1984): Prevalence and survival of Toxocara canis eggs in the urban environment of Perth, Australia. Vet. Parasitol., 16(3 - 4): 303 - 311. DOI: 10.1016/0304-4017(84)90048-7

DuWEL, D. (1984): The prevalence of Toxocara eggs in the sand in children's playgrounds in Frankfurt. Annals of Tropical Medicine and Parasitology, 78(6): 633 - 636

FISHER, M. (2003): Toxocara cati: an underestimated zoonotic agent. Trends Parasitol., 19(4): 167 - 170. DOI: 10.1016/S1471-4922(03)00027-8

GAWOR, J., BORECKA, A., ZARNOWSKA, H., MARCZYŃSKA, M., Dobosz, S.(2008): Environmental and personal risk factors for toxocariasis in children with diagnosed disease 
in urban and rural areas of central Poland. Vet. Parasitol., 155(3 - 4): 217 - 222. DOI: 10.1016/j.vetpar.2008.05.016 Gortari, C., Cazau, C., Hours, R. (2007): Hongos nematófagos de huevos de Toxocara canis en un paseo público de La Plata, Argentina. Rev. Iberoam. Micol., 24(1): $24-28$

Guerriero, J., McCall, J. W., Genchi, C. (2002): The use of macrocyclic lactones in the control and prevention of heartworm and other parasites in dogs and cats. In: VERCRUYSSE, J., REW, R. S. (Eds.) Macrocyclic lactones in antiparasitic therapy. New York, USA: CABI Publishing, pp. $353-370$

Habluetzel, A., Traldi, G., Ruggieri S., Attili, A. R., Scuppa, P., MARchetTi, R., Meneghini, G., Esposito, F. (2003): An estimation of Toxocara canis prevalence in dogs, environmental egg contamination and risk of human infection in the Marche region of Italy. Vet. Parasitol., $113(3$ - 4): 243 - 252. DOI: 10.1016/S03044017(03)00082-7

Legrottaglie, R., Papini, R., Capasso, R., Cardini, C. (2003): Prevalence of Toxocara canis eggs in dog faecal deposits from urban areas of Pisa, Italy. Helminthologia, 40(3): 173-175

MAŚNIK, E. (2000): [Relationships between the prevalence of Toxocara eggs in dogs' faeces and soil]. Wiad. Parazytol., 46(2): $239-244$

MARtin, U. O., Demonte, M. A., (2008): Urban contamination with zoonotic parasites in the central region of Argentina. Medicina (Buenos Aires), 68(5): 363 - 366

MasudA, Y., Kishimoto, T., Ito, H., TsuJ, M. (1987): Visceral larva migrans caused by Trichuris vulpis presenting as a pulmonary mass. Thorax, 42(12): 990 - 991. DOI: 10.1136/thx.42.12.990

Matsuo, J., NAKashio, S. (2006): Prevalence of fecal contamination in sandpits in public parks in Sapporo City,
Japan. Vet. Parasitol., $128(1-2): 115$ - 119. DOI: 10.1016/j.vetpar.2004.11.008

Morrone, A., Paradisi, M., Paradisi, A., Valenzano, M., FAZIO, R., ForNARI, U., FrANCO, G. (2008): Autochthonous creeping eruption in an Italian child. Am. J. Clin. Dermatol., 9(3): 205 - 206

NoOr AzIan, M. Y., SAKhone, L., Lokman Hakim, S., YusRi, M. Y., NuRUlSyAMZAWATY, Y. ZuhaiZAM, A. H., MoHD Rodi, I., MASLAWATY, M. N. (2008): Detection of helminth infections in dogs and soil contamination in rural and urban areas. Southeast Asian J. Trop. Med. Public Health, 39(2): 205 - 212

Paquet-Durand, I., HernándeZ, J., Dolz, G., ZuÑIgA, J. J. R., SCHNEIDER, T., EPE, C. (2007): Prevalence of Toxocara spp., Toxascaris leonina and ancylostomidae in public parks and beaches in different climate zones of Costa Rica. Acta Tropica, 104(1): 30 - 37. DOI: 10.1016/j.acta tropica.2007.06.011

RICHARDS, D. T., LEWIS, J. W. (2001): Fecundity and egg output by Toxocara canis in the red fox, Vulpes vulpes. J. Helminthol., 75(2): 157 - 164. DOI: 10.1079/JOH2001066 Rinaldi, L., Buggeri, A., Carbone, S., Musella, V., Catelan, D., Veneziano, V., Cingoli. G. (2006): Canine faecal contamination and parasitic risk in the city of Naples (southern Italy). BMC Vet. Res., 2: 29. DOI: 10.1186/17466148-2-29

Tavassoli, M., Hadian,M., Charesaz, S., JaVadi, S. (2008): Toxocara spp eggs in public parks of Urmia City, West Azerbaijan Province Iran. Iran. J. Parasitol., 3(3): 24 $-29$

TinOCO-Gracia, L., BARrERAI-SERranO, A., LOPEZVAlencia, G., TAmayo-Sosa, .R., Rivera-Henry, M., QUINTANA-RAMÍREZ, Q. (2007): Frequency of Toxocara canis eggs in public parks of the urban area of Mexicali, B.C., Mexico. J. Anim. Vet. Adv., 6(3): 430 - 434. DOI: 10.3923/javaa.2007.430.434

ACCEPTED MAY 28, 2012 